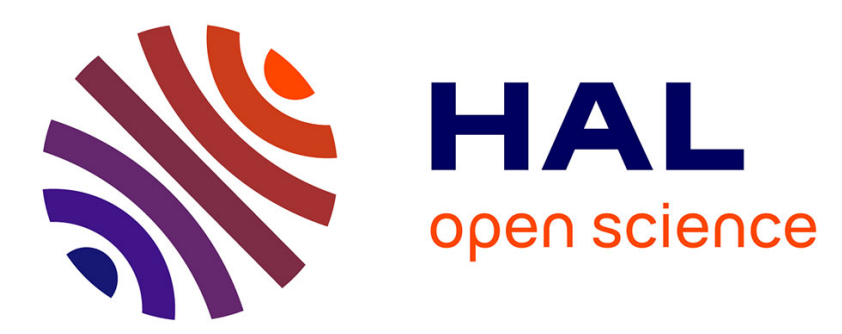

\title{
A neuronal substrate for a state-dependent modulation of sensory inputs in the brainstem
}

Didier Le Ray, Laurent Juvin, Tanguy Boutin, François Auclair, Réjean Dubuc

\section{To cite this version:}

Didier Le Ray, Laurent Juvin, Tanguy Boutin, François Auclair, Réjean Dubuc. A neuronal substrate for a state-dependent modulation of sensory inputs in the brainstem. European Journal of Neuroscience, 2010, 32 (1), pp.53-59. 10.1111/j.1460-9568.2010.07276.x . hal-02347258

\section{HAL Id: hal-02347258 \\ https://hal.science/hal-02347258}

Submitted on 7 Nov 2019

HAL is a multi-disciplinary open access archive for the deposit and dissemination of scientific research documents, whether they are published or not. The documents may come from teaching and research institutions in France or abroad, or from public or private research centers.
L'archive ouverte pluridisciplinaire $\mathbf{H A L}$, est destinée au dépôt et à la diffusion de documents scientifiques de niveau recherche, publiés ou non, émanant des établissements d'enseignement et de recherche français ou étrangers, des laboratoires publics ou privés. 
Journal section /Associate Editor: Neurosystems / Andrea Nistri

\section{Title: A neuronal substrate for a state-dependent modulation of sensory inputs in the brainstem}

\section{Didier Le Ray ${ }^{3}$, Laurent Juvin ${ }^{2}$, Tanguy Boutin ${ }^{2}$, François Auclair $^{2} \&$ Réjean Dubuc ${ }^{1,2}$}

10

${ }^{1}$ Département de kinanthropologie, Université du Québec à Montréal, Montréal (Québec)

Canada, H3C $3 P 8$

${ }^{2}$ Groupe de Recherche sur le Système Nerveux Central, Département de Physiologie, Université

15 de Montréal, Montréal (Québec), Canada, H3C 3J7

${ }^{3}$ Université de Bordeaux, CNRS, Laboratoire Mouvement Adaptation Cognition, Bât. B2A, 146 rue Léo Saignat 33076 Bordeaux, France

Correspondance to:

Dr Réjean Dubuc

Université du Québec à Montréal,

Département de kinanthropologie,

C.P. 8888 , Succ. Centre-Ville,

Montréal (Québec), Canada H3C 3P8

25

Tel: (514) 3435729

Fax: (514) 3436611

Email: dubuc.rejean@uqam.ca

30 Running title: MLR-induced depression of sensory inputs

Number of pages: 21

Number of figures: 3

Number of words for Whole manuscript/Abstract/Introduction: 5604/119/427

Keywords: MLR; Muscarinic; Sensory integration; Locomotion; Lamprey 


\begin{abstract}
Central networks modulate sensory transmission during motor behavior. Sensory inputs may thus have distinct impacts according to the state of activity of the central networks. Using an in

5 vitro isolated lamprey brainstem preparation, we investigated whether a brainstem locomotor center, the mesencephalic locomotor region (MLR), modulates sensory transmission. The synaptic responses of brainstem reticulospinal (RS) cells to electrical stimulation of the sensory trigeminal nerve were recorded before and after electrical stimulation of the MLR. The RS cell responses were significantly reduced by MLR stimulation. Moreover, the

10 depression of sensory transmission increased with the stimulation intensity of the MLR. Bath perfusion of atropine prevented the depression of sensory transmission, indicating that muscarinic receptor activation is involved. Previous studies have shown that, upon stimulation of the MLR, behavioral activity switches from a resting state to an active-locomotor state. Therefore, our results suggest that a state-dependent modulation of sensory transmission to RS

15 cells occurs in the behavioral context of locomotion and that muscarinic inputs from the MLR are involved.
\end{abstract}




\section{Introduction}

The neural control of movements is based on interactions between centrally generated motor commands and incoming sensory inputs. For instance, central neural networks require sensory

5 inputs to adapt motor behavior to environmental conditions. Reciprocally, the central neural networks gate sensory transmission in a "state"-dependent fashion. Transmission of sensory signals can be modulated according to whether the animal is resting, standing or in movement (Graham Brown, 1911; Grillner, 1973; Grillner and Rossignol, 1978; Rossignol and Gauthier, 1980). Similarly, pain sensitivity is modulated in sleep vs. wake conditions (Foo and Mason,

10 2003). There are multiple examples of state-dependent modulation of sensory transmission in the mammalian spinal cord (Rossignol et al., 1981; Hultborn, 2001; Krawitz et al., 2001). However, the underlying cellular mechanisms have not been identified yet.

Even less is known about modulation of sensory transmission in supraspinal networks. Activity of brainstem cholinergic neurons can be adapted during the sleep-wake cycle (El

15 Mansari et al., 1989; Kayama et al., 1992). Moreover, cholinergic neurons have been reported to play an important role in modulation of sensory transmission in the brainstem of mammals (Fernández de Sevilla et al., 2006). The cellular mechanisms of the muscarinic modulation have been described with little information relative to the specific pathways involved and to the behavioural circumstances during which the modulation was exerted. Thus, we began to examine

20 state-dependent modulation of sensory transmission in the brainstem of lampreys, an animal preparation that has allowed us to examine cellular mechanisms as well as the detailed connectivity in relation to locomotor behavior. We have recently reported a powerful muscarinic modulation of sensory transmission or trigeminal inputs to the reticulospinal cells in the lamprey 
brainstem (Le Ray et al., 2004). In this study, we showed that the local perfusion of a muscarinic agonist either on the reticulospinal or on the trigeminal relay cells induced a depression of synaptic transmission. However despite the characterisation of the cellular mechanisms involved, the origin and the functional relevance of this cholinergic modulation remained to be established.

5 We now show that trigeminal sensory transmission is depressed following the activation of the MLR. This effect was prevented by adding a muscarinic receptor antagonist to the perfusing Ringer's. We propose that the MLR is the origin of the previously described muscarinic modulation of sensory transmission from the trigeminal inputs to reticulospinal cells. The role of this modulation could be to adapt the responsiveness to the environment depending of the behavioural state of the animal (locomotion vs. rest). We now describe a neural pathway involved in modulating sensory transmission to brainstem neurons in relation to locomotion.

\section{Methods}

Electrophysiological experiments were performed in isolated in vitro brainstem preparations

15 from larval lampreys, Petromyzon marinus $(\mathrm{n}=45)$, whereas immunohistochemistry was performed in adult animals $(\mathrm{n}=11)$. The larval lampreys were collected from the Morpion Stream near Lake Champlain in southern Québec, whereas the reproductive adult lampreys were collected from the Great Chazy River near Lake Champlain (NY, USA) and from the St-Mary's River between Lake Superior and Lake Huron (ON, Canada). All procedures conformed to the

20 guidelines of the Canadian Council on Animal Care and were approved by the University Animal Care and Use Committees at the Université de Montréal and the Université du Québec à Montréal. Special care was taken to minimize suffering as well as the number of animals used in the experiments. 


\section{Electrophysiology}

Under tricaine methanesulphonate anesthesia (MS 222, $100 \mathrm{mg} / \mathrm{L}$, Sigma, Oakville, ON, Canada), the animals were incised along the ventral midline and eviscerated. The dissection was performed as previously described (Le Ray et al., 2004) in cold Ringer's with the following composition (in $\mathrm{mM}$ ): $130 \mathrm{NaCl}, 2.1 \mathrm{KCl}, 2.6 \mathrm{CaCl}_{2}, 1.8 \mathrm{MgCl}_{2}, 4 \mathrm{HEPES}, 4$ Dextrose, 1 $\mathrm{NaHCO}_{3}$. The preparation was pinned down to the Sylgard bottom of an experimental chamber perfused with oxygenated cold Ringer's $\left(9^{\circ} \mathrm{C} ; \mathrm{pH} 7.4\right)$. A complete transection was made above the mesencephalon for decerebration purposes and a lesion was made at the obex to separate the brainstem from the spinal cord (Fig. 1A). During the course of the experiments, the recording chamber was constantly perfused with Ringer's ( $2 \mathrm{ml} / \mathrm{min})$.

Lamprey reticulospinal (RS) neurons $(n=85)$ in the middle rhombencephalic reticular nuclei (MRRN) were impaled under visual guidance with sharp glass microelectrodes (4M K-acetate, $\sim 100 \mathrm{M} \Omega$; Fig. 1A). The intracellular signals were recorded from the largest reticular neurons in the MRRN, including the Müller cells (see Rovainen, 1982) with an Axoclamp 2A (Axon

15 Instruments Inc., Foster City, CA) and directed to a computer (sampling rate: $10 \mathrm{kHz}$ ) through a TL-1 DMA interface (Axon Instruments Inc.). In order to reduce the number of animals used in these experiments, one to five RS neurons were recorded per preparation. A long period of time (90 to $120 \mathrm{~min}$ ) was allocated between successive RS neuron impalements to permit full recovery of the preparation.

The effects of drug application and trigeminal nerve stimulation were all tested at resting membrane potential $(-76.8 \pm 0.7 \mathrm{mV} ; \mathrm{n}=74$; from $-66 \mathrm{mV}$ to $-90 \mathrm{mV})$. Electrical stimulation of either the ipsi- or contralateral trigeminal sensory nerve (single shocks of $1.5 \mathrm{~ms}$ duration at $0.1 \mathrm{~Hz})$ and of the MLR $(1.5 \mathrm{~ms}$ shocks repeated at 3-10 Hz during 15-40 s) were performed with 
homemade glass-coated tungsten microelectrodes (4-5 M $\Omega$ ) using a Grass S88 stimulator (Grass Instrument Co., Quincy, MA). The trigeminal-evoked PSPs were first monitored for several minutes under control condition. They were then measured after MLR stimulation when the MLR-induced depolarization of the RS neuron had ceased and the membrane potential of the

5 recorded cell had returned to control levels. Therefore, changes in trigeminal PSPs did not result from an indirect effect of the RS neuron being depolarized, such as a shunt due to a conductance opening. Atropine (10 $\mu \mathrm{M}$; Sigma) freshly dissolved in the Ringer's solution was bath applied and tested on 7 RS neurons (from 6 different preparations). In 5 RS cells, the input resistance $\left(\mathrm{R}_{\text {in }}\right)$ and the area of a 20-sec MLR stimulation-induced plateau were measured in normal

10 Ringer's and during atropine perfusion.

\section{Immunohistochemistry}

The presence of muscarinic receptors was examined using immunohistochemistry in spawning-phase adult lampreys $(\mathrm{n}=11)$ ranging from 45 to $55 \mathrm{~cm}$ in total body length. Adult lampreys were chosen to carry out these experiments because they show more fully differentiated

15 morphological characteristics (i.e. dendritic arbors) than larval animals. The dissection was similar to that for electrophysiological experiments in larvae. The preparations were fixed by immersion in a solution mixed with $2 \%$ paraformaldehyde/ $0.2 \%$ picric acid in $0.1 \mathrm{M}$ phosphate buffer saline (PBS) at $4^{\circ} \mathrm{C}$, pH 7.4 for 6 hours. After spending one night in a $30 \%$ sucrose solution at $4{ }^{\circ} \mathrm{C}$, the brains were frozen in 2-methylbutane. The rhombencephalon was then cut in

$2025 \mu \mathrm{m}$-thick transverse sections using a cryostat (American Optical, Buffalo, NY) and mounted on gelatin-coated slides. Sections were dried on a warming plate at $37^{\circ} \mathrm{C}$ overnight. All subsequent steps were carried out at room temperature unless specified otherwise. The next day, the sections were first rinsed 3 times with PBS and endogenous peroxidase activity was blocked 
by incubation in a solution of $0.3 \%$ peroxide and $0.1 \%$ sodium azide for $10 \mathrm{~min}$. The sections were rinsed 3 times in PBS and then incubated in a solution of PBS containing 5\% normal rabbit serum (NRS) and $0.4 \%$ Triton X-100 for 1 hour, followed by a solution of PBS containing $1 \%$ NRS, $0.1 \%$ Triton X-100 and the primary antibody M35 (Argene Inc., N. Massapequa, NY)

5 diluted 1:200 for 20 hours at $4^{\circ} \mathrm{C}$. The next day, the sections were rinsed 3 times in PBS and then incubated in a solution of PBS containing 1\% NRS, $0.1 \%$ Triton X-100, and a biotinylated rabbit anti-mouse antibody diluted 1:100 (Chemicon, Temecula, CA) for 1 hour. The sections were rinsed 3 times in PBS, incubated for 1 hour in a solution of the standard Vectastain Elite ABC kit (Vector, Burlingame, CA,) as prescribed by the manufacturer, and then rinsed again 3 times in

10 PBS. The immunohistochemical staining was revealed by incubating the sections in a solution of $0.05 \%$ diaminobenzidine tetrahydrochloride in PBS for $5 \mathrm{~min}$. The sections were then rinsed 3 times in PBS, dehydrated in alcohol, cleared with xylene and mounted with Entellan (VWR International, Montréal, QC, Canada).

Photomicrographs were taken with a 20X Plan Fluor objective (numerical aperture $=0.50$ )

15 fitted on a Nikon Eclipse E600 microscope equipped with a DXM1200 digital camera. The contrast and brightness of photomicrographs were adjusted, and the figures designed using CorelDraw 12 (Corel Corp., Ottawa, ON, Canada) software.

The ability of the M35 pan-muscarinic monoclonal antibody to bind specifically to muscarinic cholinergic receptors of lampreys was previously confirmed using Western Blot

20 analysis (Smetana et al., 2007). In the present experiments, omitting the M35 primary antibody from the immunohistochemical procedure resulted in a complete absence of labeling.

\section{Statistical Analysis}

The area of the PSPs evoked by the stimulation of the trigeminal nerve in RS cells was 25 compared before (control condition) and after MLR stimulation (post-stimulation 
condition). All measurements were made when the RS cell membrane potential was stable. The mean area of the trigeminal PSPs (in mV.ms) was calculated from the area of 10 PSPs recorded in each $\mathrm{RS}$ cell. Statistical comparisons were then made after averaging the mean areas of the different $\mathrm{RS}$ cells (mean area \pm SEM). A total of 74 neurons were recorded in 34

5 animals. To test for sample independence when more than one cell were recorded per animal, the analyses on 74 neurons were compared to those when only one cell was taken per animal (34 neurons). There were no statistical differences between the analysis of 34 neurons and that of the entire population of 74 neurons. Therefore, all 74 neurons were included in the analysis.

10 The statistical significance of possible changes in the area of the PSPs was tested using a paired $t$-test when two groups were compared; a one-way ANOVA for repeated measures was used when more than two groups were compared. The ANOVA was followed by a Tukey's post hoc test when significance was achieved. The sphericity assumption was verified using the Mauchly criterion. If rejected, a Greenhouse-Geisser correction was

15 performed. The same statistical analyses were used when comparing the $\mathbf{R}_{\text {in }}$ and the area of the depolarization plateaus.

For all the statistics, (n) refers to the number of neurons. Data are expressed as mean \pm SEM. Differences were considered as statistically significant when $\boldsymbol{P}$ value was less than 0.05. All the statistics were obtained using both Prism software (GraphPad software, 20 inc., La Jolla, CA, USA) and SPSS Statistics 17.0 software (SPSS inc., Chicago, IL, USA). Some of the data were normalized for illustration (see histograms in Fig. 1). Normalization was made with respect to control values after averaging the absolute control values in order to obtain a SEM value for control values as well. 


\section{Results}

MLR activation transiently depressed trigeminal-evoked EPSPs

Trains of stimuli applied for 15-40 s in the frequency range that was previously shown to

5 elicit locomotion (2-10 Hz; Sirota et al., 2000; Le Ray et al., 2003) markedly depressed sensory transmission to RS neurons in the MRRN. In the example illustrated in Figure 1B, the trigeminal sensory nerve on one side was stimulated at $0.1 \mathrm{~Hz}$ before and after applying a tonic $15 \mathrm{~s}, 3 \mathrm{~Hz}$ stimulation to the MLR. Stimulation of the MLR elicited a sustained depolarization in the recorded RS neuron (not shown, but see Le Ray et al., 2003). Once the stimulation of the

10 trigeminal nerve was resumed after the MLR-induced RS neuron depolarization had stopped, the area of the trigeminal EPSPs was reduced by about $50 \%$, from $162.6 \pm 11.9$ to $79.5 \pm 3.8 \mathrm{mV} \cdot \mathrm{ms}$ (Fig. 1B top). On average ( $\mathrm{n}=74$ cells), the area of the synaptic responses was significantly decreased from $100 \pm 14.5 \%$ (before) to $70.1 \pm 11.1 \%$ after MLR stimulation $\left(t_{73}=5.689\right.$, $\boldsymbol{P}=\mathbf{0 . 0 0 2}$; Fig. 1C, left). The EPSPs progressively recovered after $20 \mathrm{~min}$. The $\mathrm{R}_{\mathrm{in}}$ of $5 \mathrm{RS}$ cells

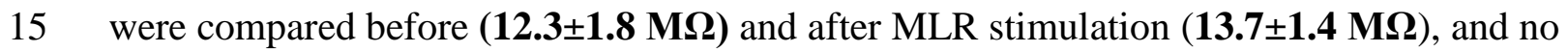
significant changes were found $\left(\boldsymbol{F}_{\mathbf{3}, \mathbf{1 6}}=\mathbf{0 . 7 9 2 1}, \boldsymbol{P}=\mathbf{0 . 5 2} ;\right.$ Fig.1D $)$.

The muscarinic antagonist atropine $(10 \mu \mathrm{M})$ was tested on the MLR ability to induce a depression of trigemino-reticular inputs in 7 RS neurons (out of the 74 RS neurons analyzed above). Under atropine, the synaptic responses were not depressed after MLR stimulation ( $n=7$; $100 \pm 6.4 \%$ vs. $95.1 \pm 12.1 \%, \boldsymbol{t}_{\mathbf{6}}=\mathbf{0 . 7 1 7}, \boldsymbol{P}=\mathbf{0 . 5 1}$; Fig. $1 \mathrm{C}$, right; Fig $1 \mathrm{~B}$ bottom). In the same 5 cells into which the $\mathrm{R}_{\text {in }}$ was measured before and after MLR stimulation, it was also measured after adding atropine. We found that $\mathrm{R}_{\mathrm{in}}$ did not change consecutive to atropine perfusion ( $\mathrm{n}=5$; $12.3 \pm 1.8 \mathrm{M} \Omega$ vs. $12.9 \pm 0.4 \mathrm{M} \Omega ; \boldsymbol{F}_{\mathbf{3}, \mathbf{1 6}}=\mathbf{0 . 7 9 2 1}, \boldsymbol{P}=\mathbf{0 . 5 2} ;$ Fig. 1D). Moreover the area of the MLRinduced sustained depolarization remained unchanged after atropine perfusion $(\mathrm{n}=5 ; 100 \pm 9.5 \%$ 
vs. $105.1 \pm 10.2 \% ; \boldsymbol{t}_{\mathbf{4}}=\mathbf{0 . 5 8 4 7}, \boldsymbol{P}=\mathbf{0 . 5 9} ;$ Fig. $\left.1 \mathrm{E}\right)$. Taken together, these results indicate that the MLR-induced depression of the RS neuron response to trigeminal nerve stimulation is largely mediated by muscarinic acetylcholine receptors. In 3 experiments, the caudal half of the rhombencephalon (below the MRRN) was removed to eliminate most rhombencephalic

5 cholinergic neurons located in the tegmentum. In this reduced preparation, stimulation of the MLR still consistently depressed (100 $\pm 4.9 \%$ vs. $73.4 \pm 1.3 \%$; not illustrated) the EPSPs elicited by trigeminal stimulation.

In lampreys as in other vertebrates, stimulation of the MLR induces locomotor activity and the speed of swimming is directly proportional to the level of activation of the MLR (intensity or

10 frequency of stimulation; Sirota et al., 2000). We then tested whether the depression exerted by activation of the MLR on sensory-evoked EPSPs also depended on the level of MLR activation. Different MLR stimulation frequencies were then sequentially applied and the level of depression quantified in 6 RS neurons (from 6 different preparations). We observed that the stimulation of the MLR had significant effect over the PSPs area $\left(\boldsymbol{F}_{\mathbf{5 , 3 0}}=\mathbf{6 . 4 4 3}, \boldsymbol{P}=\mathbf{0 . 0 0 9}\right)$. The Tukey's post hoc

15 analysis revealed that after MLR stimulation at $3 \mathrm{~Hz}$, the amplitude of EPSPs tended to decrease, but not significantly $(\mathbf{8 7 . 9 \pm 6 . 7 \% , P > 0 . 0 5 )}$. However, when MLR stimulation was increased to higher frequencies $(5-6 \mathrm{~Hz} ; 7-8 \mathrm{~Hz} ; 9-10 \mathrm{~Hz})$, the EPSPs amplitude decreased

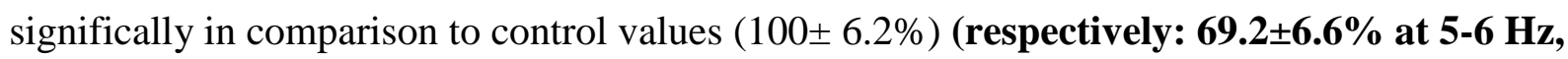
$P<0.05 ; 63.8 \pm 4.3 \%$ at $7-8 \mathrm{~Hz}, P<0.01 ; 72.8 \pm 6.4 \%$ at $9-10 \mathrm{~Hz}, P<0.05 ;$ Fig. 1F-G). Within the

20 stimulation frequency range used in this study, a maximal effect was reached at 7-8 Hz $(\mathbf{6 3 . 8} \pm \mathbf{4 . 3 \%})$ and higher stimulation frequency at 9-10 Hz did not produce further depression $(72.8 \pm 6.4 \%)$ of the EPSP area $(\boldsymbol{P}=\mathbf{0 . 9 3})$. 
Immunohistochemical identification of muscarinic receptors in rhombencephalic neurons

In order to identify the possible location where the muscarinic modulation could be exerted, an immunohistochemical detection of muscarinic receptors with the M35 pan-muscarinic monoclonal antibody was performed in the brainstem. Staining was seen in the MRRN as well as

5 more laterally in the trigeminal relay area (Fig. 2).

Giant RS Müller cells of the MRRN, showed clear cell body and proximal dendrite staining, whereas the distal dendrites located in the more ventral and lateral areas of the tegmentum seemed to lack muscarinic receptors (Fig. 2A,B). The same pattern of labeling was seen in giant RS Müller cells in the mesencephalic reticular, and in the anterior and posterior rhombencephalic reticular nuclei (not illustrated). In addition, many other immunoreactive neurons of smaller size were found in all reticular nuclei, including a periventricular population lateral to and intermingled with the giant RS Müller cells of the MRRN (Fig. 2B, arrows), and another population ventral to the motoneurons of the seventh nerve (VII; Fig. 2D, large arrow).

Many neurons were also labeled in the nucleus of the trigeminal descending tract $(\mathrm{dVn}$;

15 Northcutt, 1979), which contains the second-order trigeminal sensory neurons that project directly to RS neurons (Viana Di Prisco et al., 2005). The labeled cells were present at all rostrocaudal levels of the $\mathrm{dVn}$. More particularly, many bipolar and multipolar neurons (small arrows) were present at the level of the motor nuclei of the fifth (V; Fig. 2C) and seventh (Fig. 2D) nerves.

\section{Discussion}

In both invertebrates and vertebrates, sensory information shapes motor commands at every level of the CNS in order for movements to be adapted to external and internal conditions. In turn, the central networks modulate sensory input transmission via both pre- and post-synaptic 
mechanisms (see Clarac et al., 2000; Hultborn and Nielsen, 2007). Many studies have highlighted phase- and/or state-dependent modulation of sensory transmission in the spinal cord (for a review, see Rossignol et al., 2006). In the brainstem as well, some control mechanisms of sensory inflow have been described related to locomotor activity (Bussières and Dubuc, 1992; Alford and

5 Dubuc, 1993). The detailed connectivity and neuronal elements involved are yet to be identified. We now show in lampreys that activating the MLR induces a long lasting state-dependent depression of trigeminal sensory inputs to RS neurons and that muscarinic receptors are involved. Long lasting depression of sensory inputs has previously been described either at the spinal cord level in decerebrate cats during fictive locomotion (Gosgnach et al., 2000) or in man during walking (Voigt et al., 1998). In this work, we did not test the ability of MLR stimulation to induce a swimming behavior, but the same stimulation parameters have been used in previous studies to generate locomotor bouts in a semi-intact preparation (Sirota et al., 2000; Le Ray et al., 2003). Because of this, we can assume that the depression observed in sensory transmission in response to stimulation of the MLR is related to locomotion.

15 The MLR of lampreys contains cholinergic neurons (Le Ray et al., 2003). Because the depression of sensory transmission to RS cells was shown to be significantly reduced by the muscarinic antagonist atropine, it is likely that activation of cholinergic neurons in the MLR will play a critical role in modulating sensory transmission. The simplest hypothesis (Fig. 3) would be cholinergic neurons in the MLR projecting to both RS and trigeminal relay cell areas. The dual 20 projection is supported by the present observation that muscarinic receptors are located on both the RS neurons and the relay cells, and our previous observation that muscarinic agonists induce a sensory depression when injected either in the dVn or in the MRRN (Le Ray et al., 2004). The MLR-evoked muscarinic depression may thus occur at RS and relay cell areas. 
Other lamprey cholinergic cells have been described in the lateral periventricular reticular formation of the caudal rhombencephalon, below the level of the MRRN down to the obex and just medial to the motoneurons of the vagal and glossopharyngeal nuclei (Pombal et al., 2001). These cells are unlikely to play a significant role here because the depression of sensory transmission to MRRN RS cells induced by stimulating the MLR was elicited equally well after a transection of the rhombencephalon just caudal to the MRRN. Similarly, muscarine-sensitive neurons were recently described in the caudal rhombencephalon (Smetana et al., 2007) that were responsible for generating recurring sustained depolarization in RS cells of the MRRN. These neurons are not part of the trigemino-reticular sensory pathway and their contribution to the

10 depressive effects described in the present study is unlikely. As indicated above, removal of the caudal half of the rhombencephalon (including these muscarinosensitive cells) did not prevent the MLR-induced depression of sensory transmission..

A muscarinic modulation of sensory transmission has also been described in mammals (Fernández de Sevilla et al., 2006) where dorsal column sensory inputs to neurons in the gracilis

15 nucleus were found to be modulated by the muscarinic agonist carbachol, via both pre- and postsynaptic effects. Muscarinic modulation of glutamatergic synapses has been reported in the past, and presynaptic mechanisms have been implicated (Jiang and Dun, 1986; Scanziani et al., 1995; Bellingham and Berger, 1996; Smolders et al., 1997; Li et al., 2002). However, the source of these modulations has yet to be identified. At this stage, we cannot establish whether the 20 effects occur pre- or postsynaptically in our system.

In lampreys, the MLR command is also largely mediated by glutamate in addition to acetylcholine (Brocard and Dubuc, 2003; Le Ray et al., 2003). Moreover, glutamate receptor agonists were shown to inhibit presynaptically the vestibular inputs to lamprey RS neurons (Bussières and Dubuc, 1992) via the activation of metabotropic receptors (Alford and Dubuc, 
1993). Whether such a glutamatergic control exists in the presently investigated trigeminoreticular pathway is not established yet. Conversely, whether the muscarinic modulation is specific to the trigeminal inputs or constitutes a more general control mechanism on sensory transmission to RS neurons, as well as the involvement of the MLR in such a global modulation remains to be established. Nevertheless, the present study provides the first demonstration that the MLR, traditionally given a role as a command center for locomotion (for reviews see Whelan, 1996; Jordan, 1998; Dubuc, 2007), can directly affect the transmission in a brainstem sensorymotor pathway that has been clearly implicated in eliciting escape swimming in lampreys (Viana Di Prisco et al., 2000; Dubuc et al., 2008). The MLR has also been shown to modulate sensory transmission in higher vertebrates. For insance, startle reflexes induced by acoustic, visual or tactile stimuli are depressed by the MLR (Fendt et al., 2001). In addition, our present study shows that the level of the trigemino-reticular depression increases with the level of MLR activation, suggesting that the more intense is the locomotion induced by the MLR, the more the latter structure depresses sensory transmission. Therefore, locomotion induced in a "goal-directed"

15 manner could be associated with a state-dependent reduction of potentially disturbing sensory inputs, thereby facilitating the control exerted by central structures on the RS system.

\section{Acknowledgements:}

This study was supported by the following grants: individual and group grants from the Canadian

20 Institutes of Health Research to R.D. (CIHR, grant numbers: 15129 and 15176); individual grant from the Natural Sciences and Engineering Research Council of Canada to R.D. (NSERC, grant number: 217435- 01); group grant from the Fonds de la Recherche en Santé du Québec (FRSQ) to R.D. (Groupe de Recherche sur le Système Nerveux Central, grant number: 5249). L.J. received a fellowship from the Fondation pour la Recherche Médicale, from the Groupe de 
Recherche sur le Système Nerveux Central of the FRSQ, and a Jasper fellowship from the Université de Montréal. The authors wish to express their gratitude to D. Veilleux for her excellent technical assistance, to $\mathrm{C}$. Valiquette for his skilful programming of data analysis software and to F. Bernard for his help with figure making. We than W. D. Swink, M. K. Jones and R. Bergstedt from the Lake Huron Biological Station (MI, USA), R. McDonald and E. Achtemichuk of the Sea Lamprey Control Centre in Sault Ste. Marie (ON, Canada), and B.A. Young and W. Bouffard of the U.S. Fish and Wildlife Service of Vermont (VT, USA) for their kind supply of lampreys.

\section{Abbreviations:}

CNS, Central nervous system; $d V n$, nucleus of the trigeminal descending tract; EPSPs, Excitatory postsynaptic potentials; MLR, mesencephalic locomotor region; MRRN, middle rhombencephalic reticular nuclei; PSPs, Postsynaptic potentials; RS, Reticulospinal. 


\section{References}

Alford, S. \& Dubuc, R. (1993) Glutamate metabotropic receptor mediated depression of synaptic inputs to lampreys reticulospinal neurones. Brain Res., 605, 175-179.

Bellingham, M.C. \& Berger, A.J. (1996) Presynaptic depression of excitatory synaptic inputs to rat hypoglossal motoneurons by muscarinic M2 receptors. J. Neurophysiol., 76, 3758-3770.

Brocard, F., Bardy, C. \& Dubuc, R. (2005) Modulatory effect of substance P to the brain stem locomotor command in lampreys. J. Neurophysiol., 93, 2127-2141.

Brocard, F. \& Dubuc, R. (2003) Differential contribution of reticulospinal cells to the control of locomotion induced by the mesencephalic locomotor region. J. Neurophysiol., 90, 1714-1727.

10 Bussières, N. \& Dubuc, R. (1992) Phasic modulation of transmission from vestibular inputs to reticulospinal neurons during fictive locomotion in lampreys. Brain Res., 582, 147-153.

Clarac, F., Cattaert, D. \& Le Ray, D. (2000) Central control components of a 'simple' stretch reflex. Trends Neurosci., 23, 199-208.

Dubuc, R. (2007) Locomotor regions in the midbrain (MLR) and diencephalon (DLR) Encyclopedia of Neuroscience, 2168-2171.

Dubuc, R., Brocard, F., Antri, M., Fénelon, K., Gariépy, J.F., Smetana, R., Ménard, A., Le Ray, D., Viana Di Prisco, G., Pearlstein, E., Sirota, M.G., Derjean, D., St-Pierre, M., Zielinski, B., Auclair, F. \& Veilleux, D. (2008) Initiation of locomotion in lampreys. Brain Res. Rev., 57, 172-182.

20 El Mansari, M., Sakai, K. \& Jouvet, M. (1989) Unitary characteristics of presumptive cholinergic tegmental neurons during sleep-waking cycle in freely behaving cats. Exp. Brain Res., 76, 519-529.

Fendt, M., Li, L. \& Yeomans, J.S. (2001) Brain stem circuits mediating prepulse inhibition of the startle reflex. Psychopharmacology (Berl.), 156, 216-224. 
Fernández de Sevilla, D., Rodrigo-Angulo, M., Nuñez, A. \& Buño, W. (2006) Cholinergic modulation of synaptic transmission and postsynaptic excitability in the rat gracilis dorsal column nucleus. J. Neurosci., 26, 4015-4025.

Foo, H. \& Mason, P. (2003) Brainstem modulation of pain during sleep and waking. Sleep Med. Rev., 7, 145-154.

Gosgnach, S., Quevedo, J., Fedirchuk, B. \& McCrea, D.A. (2000) Depression of group Ia monosynaptic EPSPs in cat hindlimb motoneurones during fictive locomotion. J. Physiol., 526, 639-652.

Graham Brown, T. (1911) Studies in the physiology of the nervous system. VlII:Neural balance and reflex reversal with a note on progression in the decerebrate guinea pig. Q. J. Exp. Physiol., 4, 273-288.

Grillner, S. (1973) Locomotion in the spinal cat. In Stein, R. B., Pearson, K. G., Smith, R. S. \& Redford, J. B. (eds), Control of Posture and Locomotion, Plenum Press, New York, pp. 515533.

15 Grillner, S. \& Rossignol, S. (1978) Contralateral reflex reversal controlled by limb position in the acute spinal cat injected with clonidine i. v. Brain Res., 144, 411-414.

Hultborn, H. (2001) State-dependent modulation of sensory feedback. J. Physiol., 533, 5-13. Hultborn, H. \& Nielsen, J.B. (2007) Spinal control of locomotion - from cat to man. Acta Physiol. (Oxf.), 189, 111-121.

20 Jiang, Z.G. \& Dun, N.J. (1986) Presynaptic suppression of excitatory postsynaptic potentials in rat ventral horn neurons by muscarinic agonists. Brain Res., 381, 182-186.

Jordan, L.M. (1998) Initiation of locomotion in mammals. Ann. N.Y. Acad. Sci., 860, 83-93. Kayama, Y., Ohta, M. \& Jodo, E. (1992) Firing of 'possibly' cholinergic neurons in the rat laterodorsal tegmental nucleus during sleep and wakefulness. Brain Res., 569, 210-220. 
Krawitz, S., Fedirchuk, B., Dai, Y., Jordan, L.M. \& McCrea, D.A. (2001) State-dependent hyperpolarization of voltage threshold enhances motoneurone excitability during fictive locomotion in the cat. J. Physiol., 532, 271-281.

Le Ray, D., Brocard, F., Bourcier-Lucas, C., Auclair, F., Lafaille, P. \& Dubuc, R. (2003) Nicotinic activation of reticulospinal cells involved in the control of swimming in lampreys. Eur. J. Neurosci., 17, 137-148.

Le Ray, D., Brocard, F. \& Dubuc, R. (2004) Muscarinic modulation of the trigemino-reticular pathway in lampreys. J. Neurophysiol., 92, 926-938.

Li, D.P., Chen, S.R., Pan, Y.Z., Levey, A.I. \& Pan, H.L. (2002) Role of presynaptic muscarinic and $\mathrm{GABAB}$ receptors in spinal glutamate release and cholinergic analgesia in rats. $J$. Physiol., 543, 807-818.

Northcutt, R.G. (1979) Experimental determination of the primary trigeminal projections in lampreys. Brain Res., 163, 323-327.

Pombal, M.A., Marín, O. \& González, A. (2001) Distribution of choline acetyltransferaseimmunoreactive structures in the lamprey brain. J. Comp. Neurol., 431, 105-126.

Rossignol, S., Dubuc, R. \& Gossard, J.P. (2006) Dynamic sensorimotor interactions in locomotion. Physiol. Rev., 86, 89-154.

Rossignol, S. \& Gauthier, L. (1980) An analysis of mechanisms controlling the reversal of crossed spinal reflexes. Brain Res., 182, 31-45.

20 Rossignol, S., Julien, C., Gauthier, L. \& Lund, J.P. (1981) State-dependent responses during locomotion. In Taylor, A. \& Prochazka, A. (eds), Muscle Receptors and Movement, Macmillan, London, pp. 389-402.

Rovainen, C.M. (1982) Neurophysiology. In Hardisty, M.W. \& Potter, I.C. (eds), The Biology of Lampreys, volume 4A, Academic Press, London, pp. 1-136. 
Scanziani, M., Gahwiler, B.H. \& Thompson, S.M. (1995) Presynaptic inhibition of excitatory synaptic transmission by muscarinic and metabotropic glutamate receptor activation in the hippocampus: are Ca2+ channels involved? Neuropharmacology, 34, 1549-1557.

Sirota, M., Viana Di Prisco, G. \& Dubuc, R. (2000) Stimulation of the mesencephalic locomotor region elicits controlled swimming in semi-intact lampreys. Eur. J. Neurosci., 12, 4081-4092.

Smetana, R.W., Alford, S. \& Dubuc, R. (2007) Muscarinic receptor activation elicits sustained, recurring depolarizations in reticulospinal neurons. J. Neurophysiol., 97, 3181-3192.

Smolders, I., Bogaert, L., Ebinger, G. \& Michotte, Y. (1997) Muscarinic modulation of striatal dopamine, glutamate, and GABA release, as measured with in vivo microdialysis. $J$. Neurochem., 68, 1942-1948.

Viana Di Prisco, G., Boutin, T., Petropoulos, D., Brocard, F. \& Dubuc, R. (2005) The trigeminal sensory relay to reticulospinal neurons in lampreys. Neuroscience, $\mathbf{1 3 1}, 535-546$.

Viana Di Prisco, G., Pearlstein, E., Le Ray, D., Robitaille, R. \& Dubuc, R. (2000) A cellular mechanism for the transformation of a sensory input into a motor command. J. Neurosci., 20, 8169-8176.

Voigt, M., Vanwanseele, B. \& Riso, R.R. (1998) The human soleus Hreflex modulation during the transition from relaxed sitting to walking. In Society for Neuroscience Abstract book 1998, Vol. 24, 28th Annual Meeting of Society for Neuroscience, Los Angeles, p. 2106. Whelan, P.J. (1996) Control of locomotion in the decerebrate cat. Prog. Neurobiol., 49, 481-515. 


\section{Figure legends}

\section{Figure 1: MLR activation depresses trigeminal sensory inputs to RS neurons.}

A: Experimental setup for stimulation of a trigeminal sensory nerve and the MLR as well as recording RS cells intracellularly. B: In normal Ringer's (top), a $3 \mathrm{~Hz}$ stimulation of the MLR for $15 \mathrm{~s}$ (arrow) induced a long-lasting reduction in the size of the EPSP evoked in an intracellularly recorded RS neuron by electrical stimulation (repeated every 10s) of a trigeminal sensory nerve. The perfusion of atropine $(10 \mu \mathrm{M}$, bottom) prevented the EPSP depression induced by MLR activation. Insets: Superimposition of control (1) and post-MLR activation (2) trigeminal EPSPs. Scale bars: $2 \mathrm{mV}, 10 \mathrm{~ms}$. C: Histograms illustrating the mean reduction of the trigeminal EPSP area, expressed as the percentage of control values, after MLR activation in control Ringer's (left; $n=74$ cells) and under $10 \mu \mathrm{M}$ atropine perfusion (right; $\mathrm{n}=7$ cells). $* * *: \mathrm{p}<0.001$. D: Histograms illustrating the lack of input resistance $\left(R_{\text {in }}\right)$ changes in five tested RS neurons after MLR stimulation both in normal Ringer's (two right bars) and under atropine perfusion (two left bars). E: Histograms illustrating the lack of effect of atropine perfusion on the MLR-evoked plateau potential in five tested RS neurons. F: Averages of five trigeminal EPSPs (black traces) recorded after the MLR was stimulated for $15 \mathrm{~s}$ at four different frequencies. The traces are superimposed with the averaged control EPSP (grey traces). Scale bars: $5 \mathrm{mV}, 50 \mathrm{~ms}$. G: Histograms illustrating the mean area of the EPSPs for six neurons as in F. The values are expressed as percentage of control values. The significance of the differences from control values are indicated by $*(\mathrm{p}<0.05)$ and $* *(\mathrm{p}<0.01)$, whereas significance of the differences between the stimulation groups are indicated by $\S \S(\mathrm{p}<0.01)$. Complete recovery was always observed several tens of minutes after MLR stimulation (right bar; light grey).

\section{Figure 2: Muscarinic receptor immunoreactivity in the MRRN and the dVn.}

A,B: Photomicrographs of transverse sections through the MRRN showing large immunoreactive RS neurons and their proximal dendrites. The bottom drawings indicate the localization of the sections in the brainstem. C,D: Photomicrographs of the lateral portion of transverse sections passing through two different rostro-caudal levels of the MRRN (see

30 bottom drawings) and showing immunoreactive neurons (arrows) of different shapes in the $\mathrm{dVn}$ at the level of the motor nuclei of the fifth (V in C) and seventh (VII in D) nerves. 
Immunoreactive neurons were also located ventral to the motor nuclei of the seventh nerve (large arrow in lower left part of D) and in the ventral nucleus of the octavolateral area (VN in C,D). Scale bar: $100 \mu \mathrm{m}$.

$5 \quad$ Figure 3: Schematic illustration of a putative pathway by which the MLR could control trigeminal sensory inputs to RS neurons. Left: Trigeminal projections to reticulospinal cells in the MRRN network and the localization of the MLR. Right (enlargement of the boxed area in the left schematic): The simplest hypothesis would be that the MLR exerts a muscarinic control on the trigemino-reticular pathway at both the RS neuron and the relay cell levels.

10 Pre- and/or post-synaptic effects could be involved. 


\section{Le Ray et al}

Figure 1
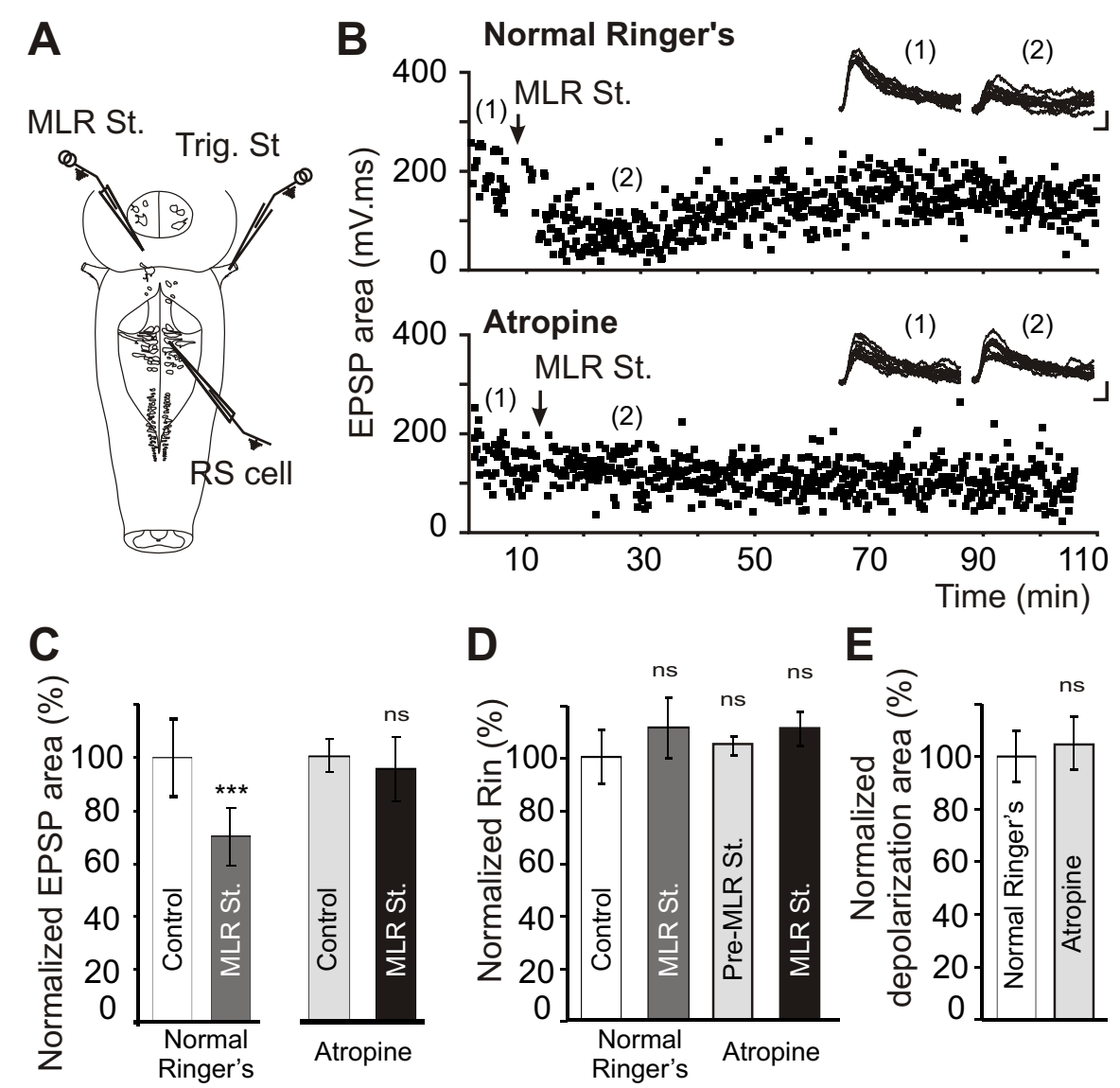

D E
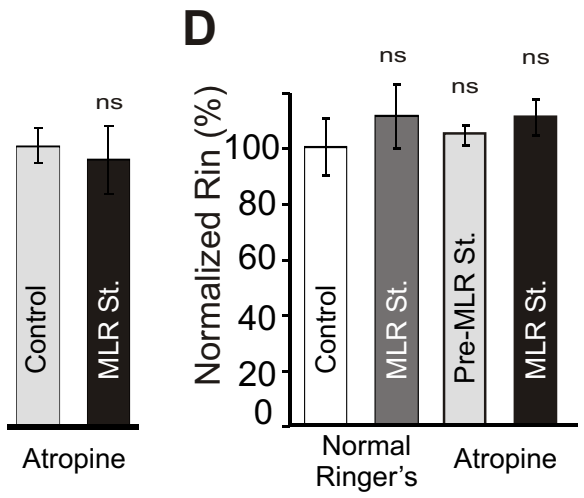

E

F

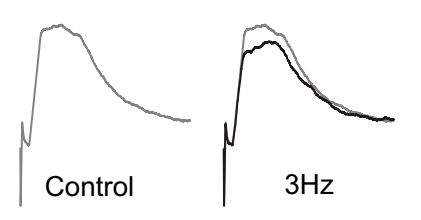

$\int_{7 \mathrm{~Hz}}$

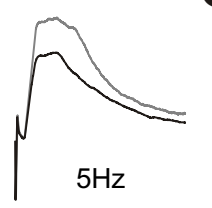

G

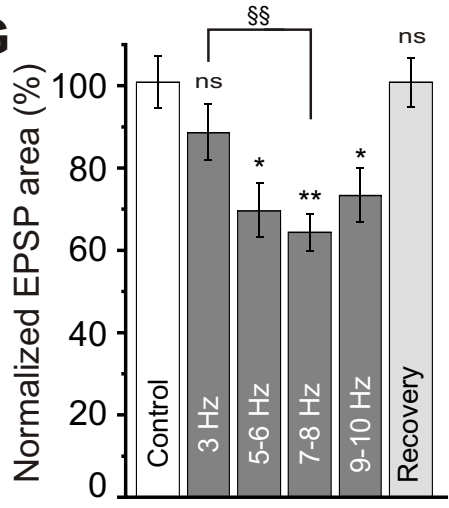




\section{Le Ray et al}

Figure 2
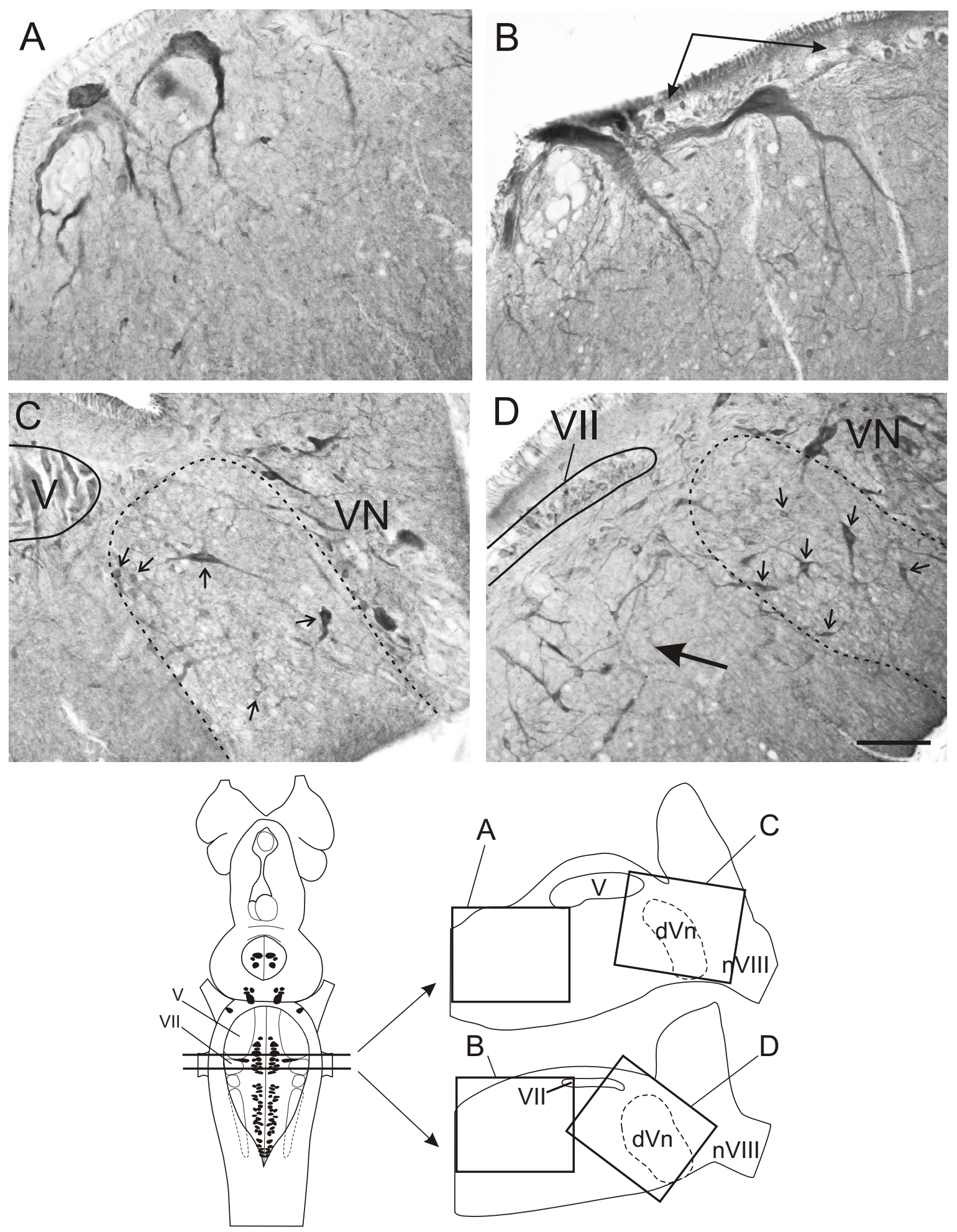
Le Ray et al

Figure 3

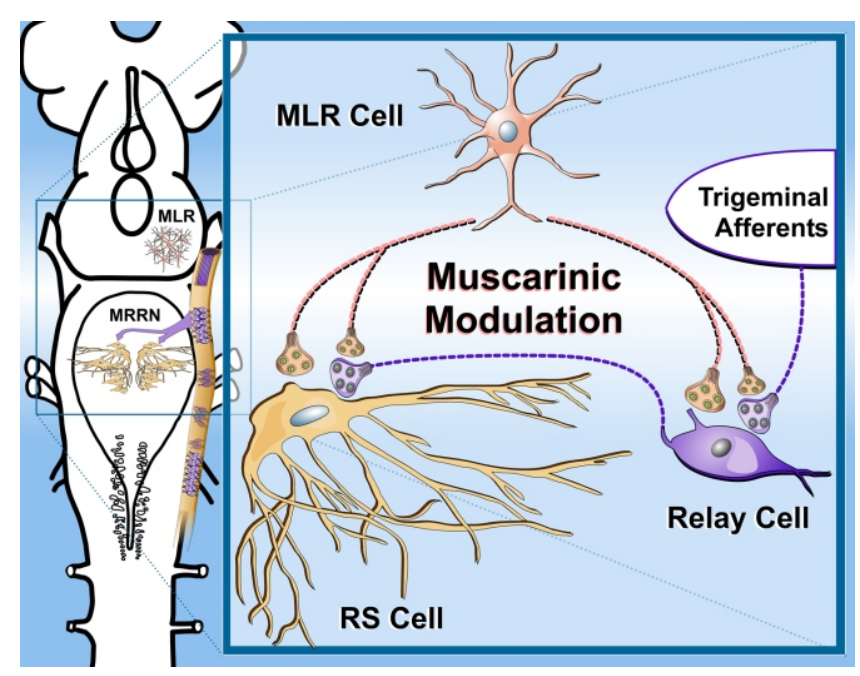

